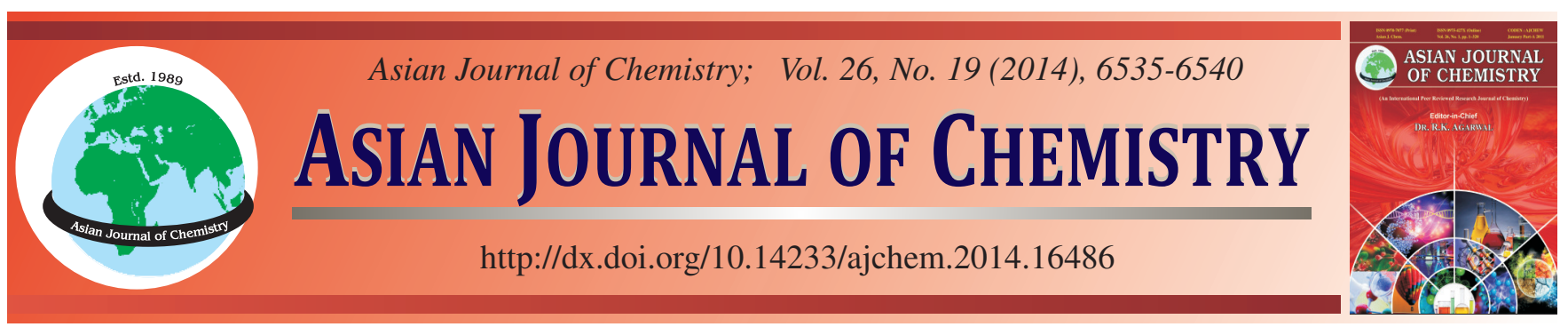

\title{
Applications of Different Techniques in Estimation of Aggregation and Thermodynamic Behaviour of Brij 58 at Different Temperatures
}

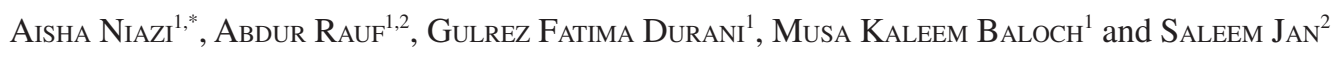

${ }^{1}$ Department of Chemistry, Gomal University, D.I. Khan, Pakistan

${ }^{2}$ Department of Chemistry, University of Science and Technology, Bannu-28100, Pakistan

*Corresponding author: E-mail: qadran2@gmail.com

\begin{abstract}
Surface tension, electrical conductivity and differential scanning calorimetry were measured for aqueous solution of surfactant Brij 58 at different temperatures. The surface tension of surfactant decreases and conductance increases as the concentration of the surfactant increases. The breakpoint, appeared in surface tension and conductivity $v s$. concentration plot, indicated the formation of molecular aggregates which are comparable and reproducible. Different thermodynamic parameters like $\pi_{\mathrm{CMC}}, \Gamma, \mathrm{a}_{\min }, \Delta \mathrm{G}_{\text {ads }}^{\circ} \Delta \mathrm{H}_{\text {ads }}^{\circ} \Delta \mathrm{S}_{\text {ads }}^{\circ}$ were calculated, which showed that $\Delta \mathrm{G}^{\circ}$ mic values of solutions was negative and became more negative with increase in temperature, whereas, $\Delta \mathrm{H}^{\circ}$ mic remained positive at all temperatures. The surface excess concentration $(\Gamma)$ was increased, which indicated the depletion of molecules from the bulk to the surface. The enthalpy change calculated by instrument was endothermic which supported our finding.
\end{abstract}

Keywords: Surfactants, Thermodynamics, Critical micelles concentration, Micellizatiom.

\section{INTRODUCTION}

A high percentage of pharmaceutically active compounds are insoluble in water having low and variable bioavailability ${ }^{1,2}$. Therefore, several techniques are in practice to increase the solubility of such drugs including the utility of the surfactants/ amphiphiles ${ }^{3-7}$. Surfactant are the substances that preferentially adsorb at an interface and lower the interfacial tension between two liquids or phases ${ }^{8}$. A large number of surfactants are available in the market, which have wide spread applications in different industries including dyestuffs, cosmetics, detergents, paints, plastic fibers, pesticides, pharmaceuticals and lubricants etc. ${ }^{9}$. The surface activity of surfactants is due to their amphiphilic structure having both a polar or hydrophilic head and a non-polar or a hydrophobic tail ${ }^{10}$. Their vital role in both fundamental and applied sciences is due to their most spectacular property to assemble into higher order structures spontaneously. This process is commonly known as self-assembly. It usually involves molecules that contain two distinct components, differing in their affinity for solutes. Molecules containing both hydrophobic and hydrophilic types of components with distinctive chemical and physical properties are said to be amphiphiles.

An amphiphilic molecule can arrange itself at the surface of the water such that the polar part interacts with the water and the non-polar part is held above the surface (either in the air or in a non-polar liquid). The presence of these molecules on the surface disrupts the cohesive energy at the surface and thus lowers the surface tension.

If the concentration of amphiphilic molecules increases above certain limit, micelles are formed and this concentration is called critical micelles concentration ${ }^{11-13}$.

These micelles also play an important role in the morphology, dynamic properties of surfactants and template synthesis of inorganic materials. In this respect various studies have been carried out in order to elucidate the effect of hydrophobic interaction of surfactant on micelle formation in solution.

The mechanism of non-ionic surfactant in aqueous solution is analogous to that of ionic surfactant from the view point that micellization is controlled by two opposing factors, the driving force for association and the factor preventing association $^{14,15}$. However, detailed studies on the micelle formation of nonionic surfactants are few in number as compared with those of ionic surfactants ${ }^{16}$. Therefore, we were intended to carry out a detailed study the micelle formation of nonionic surfactants.

\section{EXPERIMENTAL}

Polyoxyethylene glycolhexadecyl ether (Brij58) (98\%), used as surfactant, was obtained from Merck, Germany. Water used as a solvent was prepared by passing distilled water through Mixed Bed De-ionizer system and having conductance in the range of $0.3-0.8 \mu \mathrm{S} / \mathrm{cm}$. 
Surface tension measurement: Surface tension measurements of dilute aqueous Brij58 solutions and de-ionized water were made from 25 to $45^{\circ} \mathrm{C}$, by using TE 3 LAUDA Tensiometer, supplied by LAUDA, Germany. The instrument was connected to Ecoline Circulation Thermostat Model E 015T, Germany, to keep the temperature constant to $\pm 0.01{ }^{\circ} \mathrm{C}$.

Conductance measurement: The conductance of Brij58 solutions and de-ionized water was measured by InoLab Cond. 720 conductivity meter as a function of concentration and at different temperatures. The instrument was connected to Ecoline Circulation Thermostat Model E 015T, Germany, to keep the temperature constant to $\pm 0.01{ }^{\circ} \mathrm{C}$ through the jacketed glass cell used.

Differential scanning calorimetric measurement: Highsensitivity differential scanning calorimetery (DSC) has been used to determine the enthalpy of surfactant. For this purpose Perkin Elmer Diamond Differential Scanning Calorimeter Pyris-1 was used to carry out measurements. In order to control the thermal history of samples and to obtain reproducible DSC curves a strict experimental protocol was respected. Solutions were introduced into aluminium pans and left until thermal equilibrium was established before the temperature scan was started. Then the consecutive scans at a rate of $10{ }^{\circ} \mathrm{C} / \mathrm{min}$ in the temperature range $0-110{ }^{\circ} \mathrm{C}$ were started beginning with cooling followed by heating and then again cooling. Between each consecutive scans, the samples were equilibrated by giving delay time. From these scans only the last two scans in cooling and heating mode were recorded to obtain reproducible data concerning peaks.

\section{RESULTS AND DISCUSSION}

The results obtained from the surface tension measurement of surfactant polyoxyethylene glycol hexadecyl ether in aqueous media in the temperature range 298 to $318 \mathrm{~K}$ has been plotted in Figs. 1 and 2. The results showed a typical trend expected for such systems ${ }^{17-19}$. The plot of surface tension can be divided into three parts. In the first part of the plot, the surface tension decreases slowly till it reaches to a point, which we call as critical concentration of the surfactant (CC), further increase in concentration decreases the surface tension sharply and ultimately leads to a minimum value of surface tension, which showed the adsorption of surfactant at the air-water interface and then becames constant. This point is called critical micelles concentration (CMC), which showed that micellization started. Further increase in concentration of the surfactant did not alter the surface tension. However, it can increase size and change the shape of micelles ${ }^{19-22}$. At this stage, the surface became fully loaded that's why no further change in surface tension took place and as a result the surface tension remained almost constant.

Such behaviour was due to the fact that at low concentration the surfactant molecules were present in molecular state and coexisted in equilibrium with monolayer at the air-water interface. Increase in the solution concentration led to further addition of surfactant only led to further accumulation of surfactant at the air-water interface and micellization and hence the surface tension decreased, drastically ${ }^{19,21,22}$. With the increase in temperature the solvent-solute interactions changed

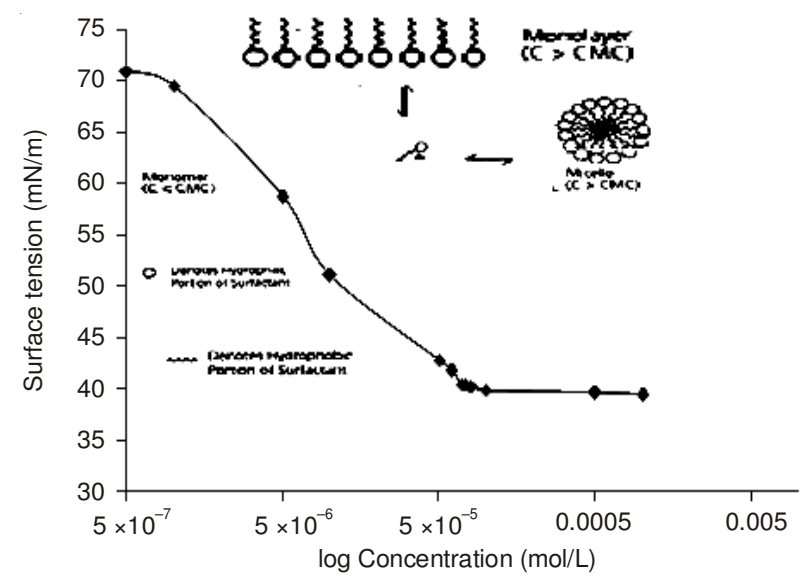

Fig. 1. Surface tension vs. $\log$ of concentration of Brij58 at $298 \mathrm{~K}$

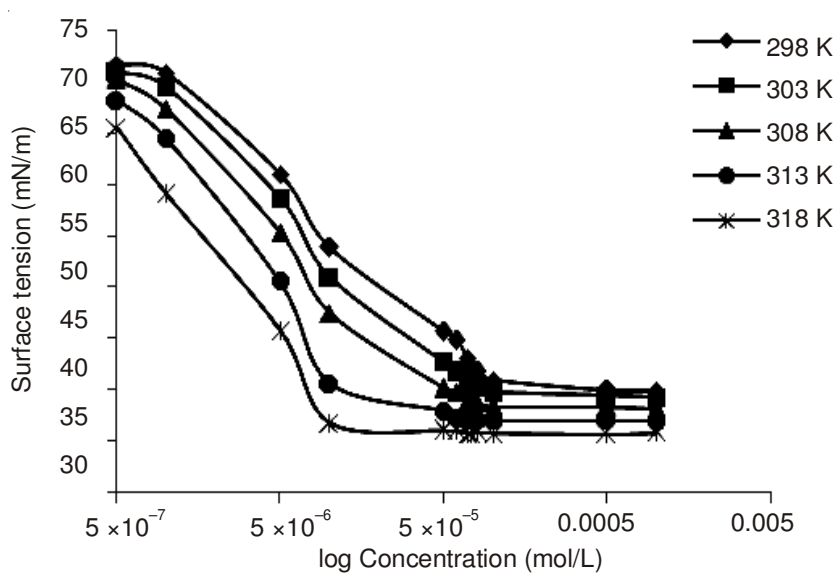

Fig. 2. Surface tension vs. $\log$ of concentration of Brij58 obtained at different temperatures

and resulted in decrease in surface tension. It can be noted that the extent of surface tension decreased with temperature was decreased with the increase in surfactant concentration, which was due to the reason that in high concentration region (C > critical micelles concentration) the surface tension was not much sensitive to surfactant concentration ${ }^{22-24}$. The critical micelle concentration was assigned to the point of intersection of two straight lines in the surface tension-concentration plots. One straight line was drawn where the surface tension decreased drastically and the other from the region where it became nearly constant.

Conductance: Fig. 3 displays the conductance of Brij58 as it varied with concentration. It can be noted that though the addition of surfactant increased the conductance but it is not linear throughout the range. Below the critical micelles concentration, the addition of surfactant to an aqueous solution caused an increase in number of charge carriers and consequently increased the conductance linearly. However, as soon as the surfactant concentration became greater than critical micelles concentration the micellization took place and the number of freely available molecules did not increase linearly in the bulk and hence the increase in conductance with concentration became less. This also means that further addition of surfactant increased the micelle concentration while the free molecules concentration remained approximately constant (at the critical micelles concentration level). Since a micelle is much larger 
than a surfactant molecule in size, it diffused more slowly through solution so was less efficient charge carrier. That is why a plot of conductivity against surfactant concentration showed a break at the critical micelles concentration ${ }^{25}$. Fig. 3 also indicated that conductance was increased with the temperature. This slight increase can be attributed to the decrease in micelles size and viscosity of solution.

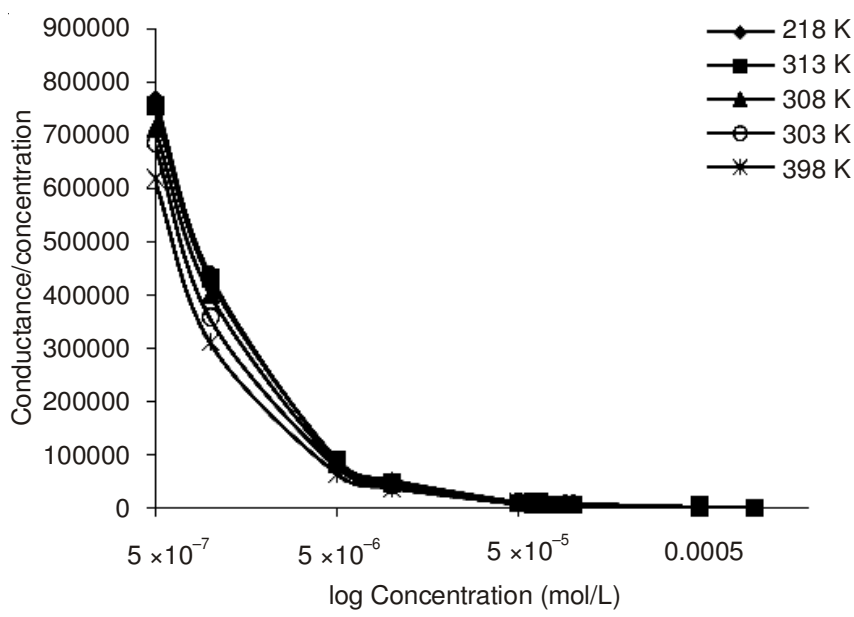

Fig. 3. Reduced conductance as a function of surfactant concentration measured at different temperatures

The critical micelles concentration obtained from these data demonstrated that it was decreased with the temperature (Fig. 8), which was due to decrease in solubility of the surfac$\operatorname{tant}^{26}$.

The degree of counter ion binding $(\beta)$ was evaluated from the slope ratios of the post-micellar and pre-micellar regions of the surfactant as:

$$
\beta=\frac{S_{2}}{S_{1}}
$$

The values of counter ion binding were plotted in Fig. 4 which showed decrease in counter ion binding with temperature.

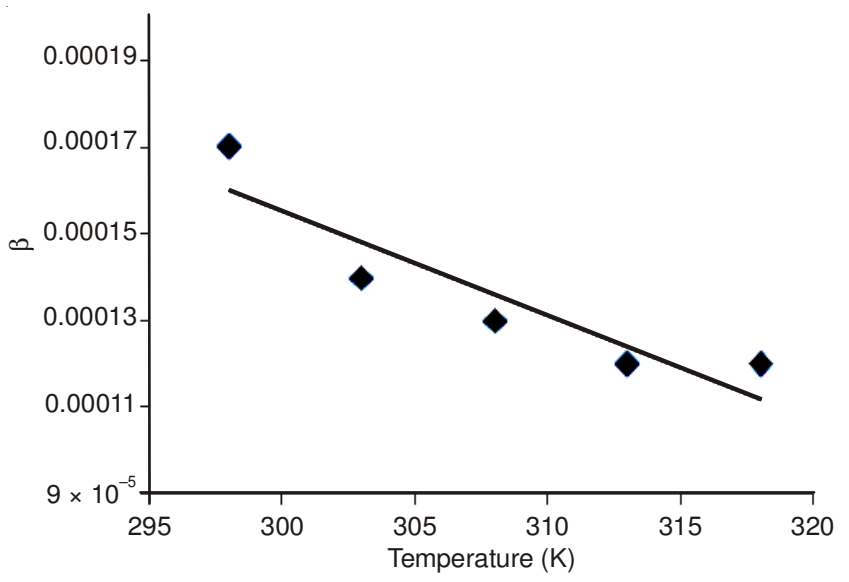

Fig. 4. Degree of counter ion binding as a function of temperature

Calorimetry: The results obtained from differential scanning calorimetry are shown in Figs. 5 and 6. The observed peaks illustrated the behaviour of surfactant and its aqueous

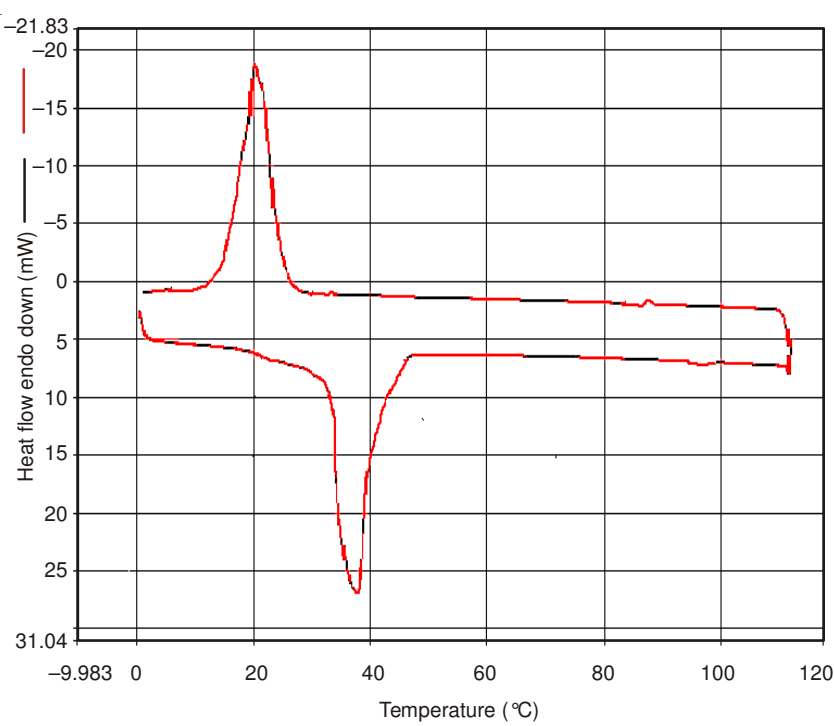

Fig. 5. Differential scanning calorimetery curve of surfactant crystals recorded in heating and cooling mode at a scanning rate of $10^{\circ} \mathrm{C} / \mathrm{min}$

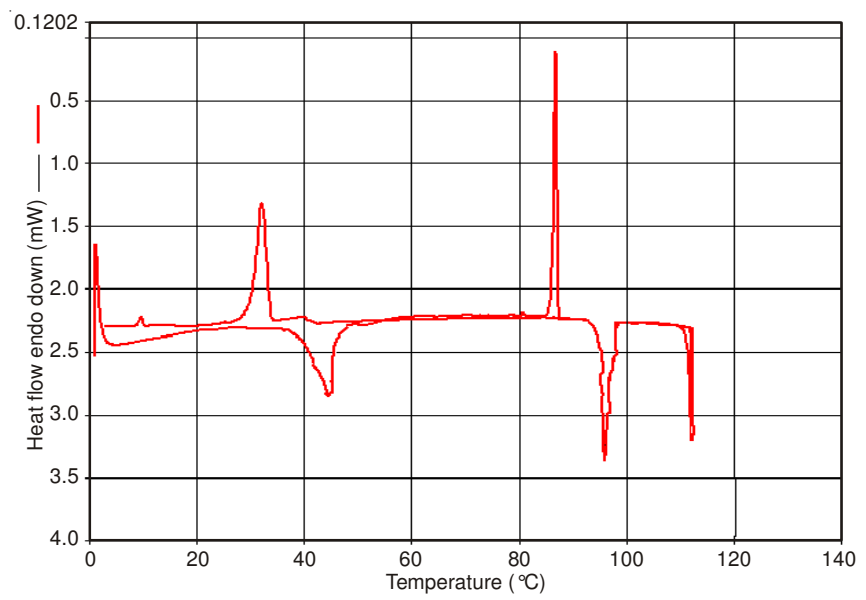

Fig. 6. Differential scanning calorimetery curve of surfactant aqueous solution recorded in heating and cooling mode at a scanning rate of $10{ }^{\circ} \mathrm{C} / \mathrm{min}$

solution. Their respective profiles were similar in the heating as well as cooling mode. In the first case (Fig. 5), a single and little bit broad peak appeared in the heating mode corresponding to the melting of Brij58 crystals. In the cooling mode similar peak was observed but with amplitude increasing and position shifted towards lower temperature. In the second case (Fig. 6), two peaks were observed, one corresponded to the melting of crystals followed by second single and sharp endothermic peak corresponded to the micellization of surfactant. Similar two peaks observed in cooling mode with increased amplitude. However, depending on the sign of thermal gradient, the observed temperatures of the peaks differed by about $10 \mathrm{~K}$ between heating and cooling. The enthalpy change calculated by instrument is endothermic which supports our enthalpy change calculated by applying formula which is also endothermic; this means that micellization process is endothermic in nature ${ }^{27,28}$.

Critical micelle concentration \& thermodynamic parameters: The process of micelle formation in aqueous solution occurs when the concentration of free amphiphiles reaches the critical micelle concentration. 
This process of the clustering of low molecular weight surfactant molecules to form micelles can be represented by the following reaction:

$$
\underset{\text { Surfactant }}{\mathrm{nS}}+\underset{\text { Counterion }}{\mathrm{pCI}} \leftrightarrow \stackrel{\mathrm{M}^{\mathrm{z}}}{\text { Micelle }}
$$

where " $\mathrm{n}$ " is the degree of aggregation, "p" is the number of counter ion binding to the micelle and " $\mathrm{z}$ " is the charge of the micelle.

$$
\mathrm{z}=\mathrm{n}-\mathrm{m}
$$

It can also be represented as the fraction ionized;

$$
\alpha=\mathrm{n}-\mathrm{m} / \mathrm{n}
$$

So,

$$
\alpha=\mathrm{z} / \mathrm{n}
$$

Mass action model: Now, considering above reaction and applying law of mass action to it we get following results.

The equilibrium constant for this reaction is:

$$
\mathrm{K}=\mathrm{X}_{\mathrm{mic}} / \mathrm{X}_{\mathrm{s}}^{\mathrm{n}} \mathrm{X}_{\mathrm{Cl}}^{\mathrm{p}}
$$

The well known thermodynamic result can be applied to the eqn. 4 to determine $\Delta \mathrm{G}^{0}$ which is the standard Gibbs free energy change,

$$
\begin{gathered}
\Delta \mathrm{G}^{0}=-\mathrm{RT} \ln (\mathrm{K}) \\
\Delta \mathrm{G}^{0}=-\mathrm{RT}\left(\ln \mathrm{X}_{\mathrm{mic}}-\mathrm{n} \ln \mathrm{X}_{\mathrm{s}}-\mathrm{p} \ln \mathrm{X}_{\mathrm{CI}}\right)
\end{gathered}
$$

If we define $\Delta \mathrm{G}^{\circ}$ mic as the standard Gibbs free energy change of micellization per mole of amphiphile i.e.;

$$
\Delta \mathrm{G}_{\text {mic }}^{\mathrm{o}}=\Delta \mathrm{G}^{0} / \mathrm{n}
$$

Then

$$
\begin{gathered}
\Delta \mathrm{G}^{\circ}{ }_{\text {mic }}=-\mathrm{RT}\left(1 / \mathrm{n} \ln \mathrm{X}_{\text {mic }}-\mathrm{n} / \mathrm{n} \ln \mathrm{X}_{\mathrm{s}}-\mathrm{p} / \mathrm{n} \ln \mathrm{X}_{\mathrm{CI}}\right) \\
\Delta \mathrm{G}^{\circ}{ }_{\text {mic }}=\mathrm{RT}\left(\mathrm{n} / \mathrm{n} \ln \mathrm{X}_{\mathrm{s}}+\mathrm{p} / \mathrm{n} \ln \mathrm{X}_{\mathrm{CI}}-1 / \mathrm{n} \ln \mathrm{X}_{\text {mic }}\right) \\
\Delta \mathrm{G}^{\circ}{ }_{\text {mic }}=\mathrm{RT}\left[(1+\mathrm{p} / \mathrm{n}) \ln \mathrm{X}_{\mathrm{cmc}}-1 / \mathrm{n} \ln \mathrm{X}_{\text {mic }}\right]
\end{gathered}
$$

The second term on the right can be neglected because it is smaller than the first term at critical micelles concentration due to the high value of "n". Thus the above equation becomes;

$$
\Delta \mathrm{G}^{\circ}{ }_{\text {mic }}=\mathrm{RT}(1+\mathrm{p} / \mathrm{n}) \ln \mathrm{X}_{\mathrm{cmc}}
$$

Considering $\mathrm{n}=0$ for ionic micelles the above equation will become;

$$
\Delta \mathrm{G}^{\circ}{ }_{\text {mic }}=\mathrm{RT} \ln \mathrm{X}_{\mathrm{cmc}}
$$

The critical micelles concentration values expressed in molarity units can be converted into mole fractions by dividing [critical micelles concentration] by the molar concentrations of water $=55.5$ mole liter $^{-1}$.

So the above equation will become;

$$
\Delta \mathrm{G}_{\text {mic }}^{\circ}=\mathrm{RT} \ln \left[\mathrm{X}_{\mathrm{cmc}} / 55.5 \mathrm{~mol} \mathrm{~L}^{-1}\right]
$$

Eqn. 13 can be used to evaluate $\Delta \mathrm{G}^{\circ}$ mic from the available critical micelles concentration values.

Thermodynamics of micellization: Different thermodynamic parameters of micellization, the $\mathrm{CMC}, \gamma_{\mathrm{CMC}}, \pi_{\mathrm{CMC}}, \Delta \mathrm{G}_{\mathrm{mic}}$, $\Delta \mathrm{H}_{\text {mic }}$ and $\Delta \mathrm{S}_{\text {mic }}$ were plotted (Figs. 7-10) and listed in Table- 1. It is clear that the critical micelle concentration of Brij58 (Fig. 8) decreases with increase in temperature. This decrease in the critical micelles concentration of surfactant with the increase in temperature is possibly due to more hydrophobicity
TABLE-1

THERMODYNAMICS PARAMETERS OF Brij58 AT DIFFERENT TEMPERATURES

\begin{tabular}{cccccccc}
\hline $\mathrm{T}(\mathrm{K})$ & $\begin{array}{c}\gamma_{\mathrm{CMC}} \\
(\mathrm{mN} / \mathrm{m})\end{array}$ & $\begin{array}{c}\pi_{\mathrm{CMC}} \\
(\mathrm{mN} / \mathrm{m})\end{array}$ & $\begin{array}{c}\Gamma \times 10^{-7} \\
\left(\mathrm{~mol} / \mathrm{cm}^{2}\right)\end{array}$ & $\begin{array}{c}\partial_{\min } \\
\left(\mathrm{A}^{\mathrm{o} 2}\right)\end{array}$ & $\begin{array}{c}\Delta \mathrm{G}^{\circ} \text { ads } \\
\mathrm{KJ} / \mathrm{mol}\end{array}$ & $\begin{array}{c}\Delta \mathrm{H}^{\circ} \text { ads } \\
\mathrm{KJ} / \mathrm{mol}\end{array}$ & $\begin{array}{c}\Delta \mathrm{S}^{\circ}{ }_{\text {ads }} \\
\mathrm{KJ} / \mathrm{mol} \mathrm{K}\end{array}$ \\
\hline 298 & 42.16 & 29.83 & 6.0201 & 0.0276 & -83.067 & -42.837 & 0.135 \\
303 & 39.92 & 31.28 & 6.4403 & 0.0258 & -82.732 & -41.827 & 0.135 \\
308 & 38.95 & 31.46 & 6.6195 & 0.0251 & -82.542 & -40.962 & 0.135 \\
313 & 37.92 & 31.68 & 7.0830 & 0.0234 & -82.388 & -40.133 & 0.135 \\
318 & 36.52 & 32.26 & 8.3626 & 0.0199 & -79.505 & -36.575 & 0.135 \\
\hline
\end{tabular}

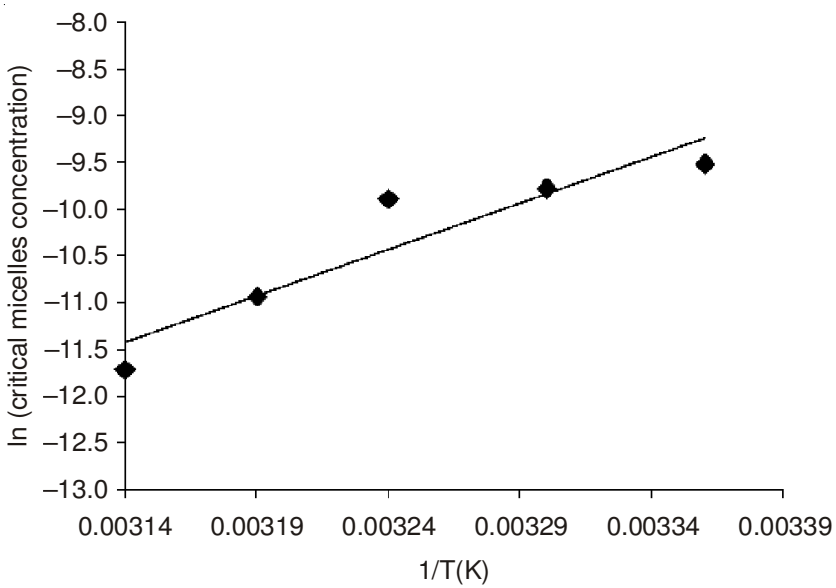

Fig. 7 ln (critical micelles concentration) of Brij58 measured as a function of inverse of temperature

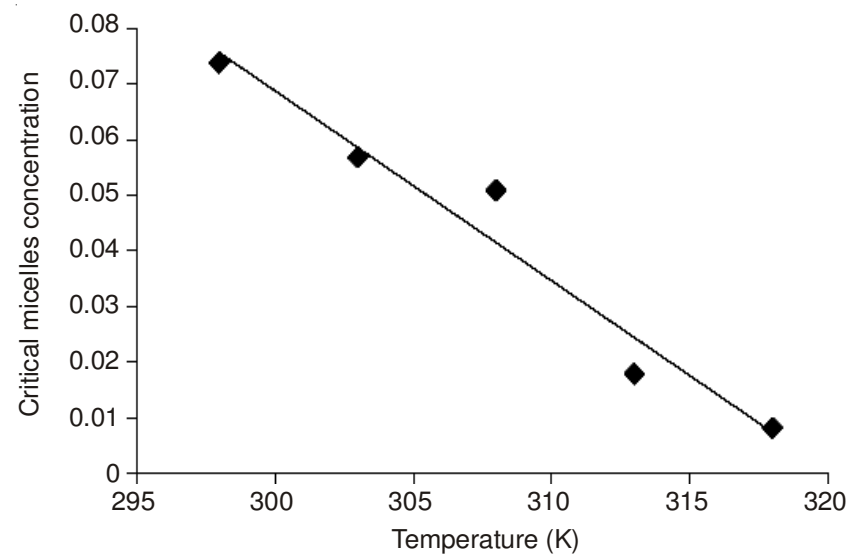

Fig. 8. Critical micelles concentration of Brij58 as a function of temperature

and dehydration of the monomers. It seems that the first effect is dominant in the temperature range studied ${ }^{9,21,24,29,30}$.

This decrease in critical micelles concentration may be due to the reason that with the increase in temperature the free energy of the system is affected ${ }^{29}$.

Results obtained for free energy of micellization were plotted in Fig. 9 as a function of temperature. $\Delta \mathrm{G}^{\circ}$ mic values of Brij58 solutions were negative and became more negative with increase in temperature, which indicated that the micellization process was spontaneous in nature and became more spontaneous with the increase in temperature. But the values were less negative than their corresponding $\Delta \mathrm{G}^{\circ}$ ads values, which indicated that work has to be done in transferring the surfactant from the surface to the micellar stage through the solution ${ }^{9,21,31}$.

On the other hand, the enthalpy of micellization can be calculated by applying the Gibbs-Helmholtz equation as follows: 


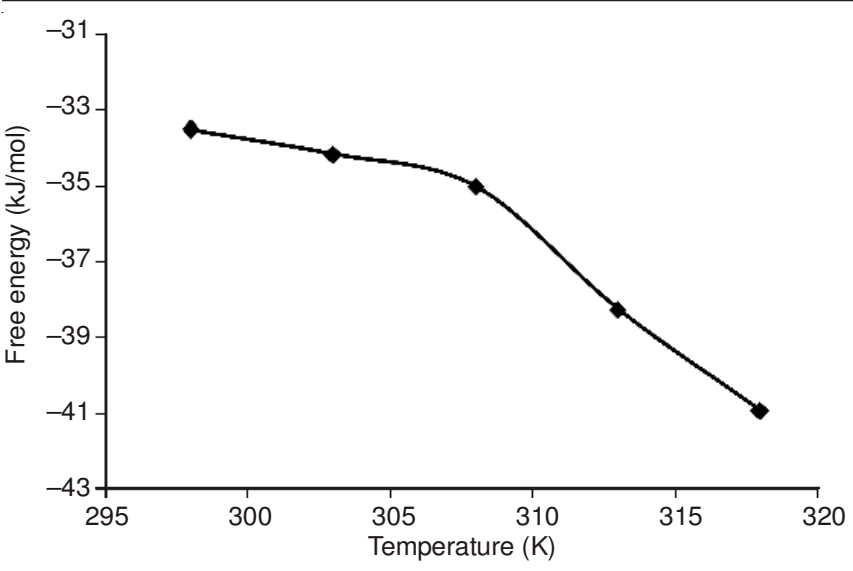

Fig. 9. Free energy of micellization of Brij58 vs. temperature

$$
\Delta{\mathrm{H}^{\circ}}_{\text {mic }}=\left[\partial\left(\Delta \mathrm{G}_{\text {mic }}^{\circ} / \mathrm{T}\right) / \partial(1 / \mathrm{T})\right]
$$

Using eqn. 12 as the expression of $\Delta \mathrm{G}^{\circ}$ mic , eqn. 14 would become as follows:

$$
\Delta \mathrm{H}^{\circ}{ }_{\text {mic }}=\mathrm{R}[\partial \operatorname{lnCMC} / \partial(1 / \mathrm{T})]
$$

In the enthalpy of micellization from the Gibbs-Helmholtz relation, the term $[\partial \operatorname{lnCMC} / \partial(1 / \mathrm{T})]$ was calculated from the slope of the tangent to a plot of $\ln$ critical micelles concentration vs. 1/T at a particular temperature. A less prominent change in $\Delta \mathrm{H}^{\circ}{ }_{\text {mic }}$ values, with changing the temperature was observed (Fig. 10). $\Delta \mathrm{H}^{\circ}{ }_{\text {mic }}$ is positive at all temperatures, this indicates the endothermic nature of micellization ${ }^{21,31}$.

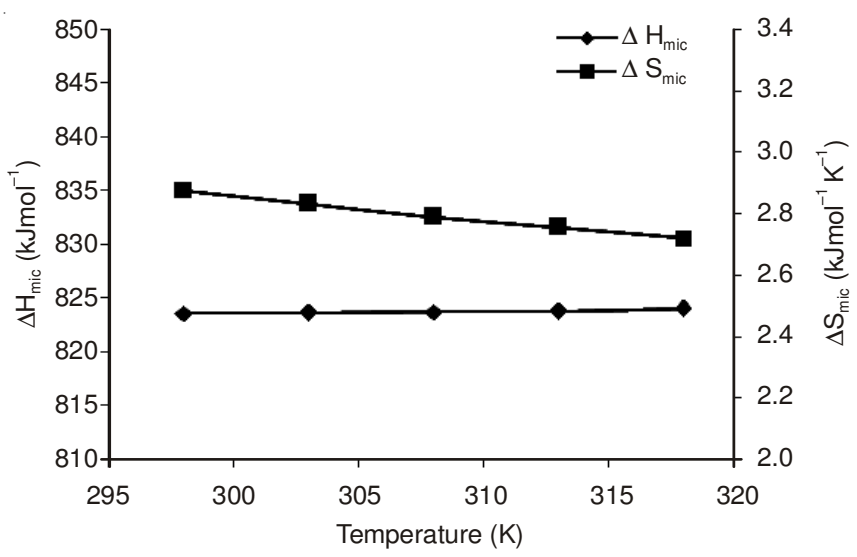

Fig. 10. Temperature dependence of $\Delta \mathrm{H}_{\text {mic }}$ and $\Delta \mathrm{S}_{\text {mic }}$

Once $\Delta \mathrm{G}^{\circ}{ }_{\text {mic }}$ and $\Delta \mathrm{H}^{\circ}$ mic have been obtained, the entropy of the micellization process can be estimated from the relation as follows:

$$
\Delta \mathrm{S}_{\text {mic }}^{\circ}=\Delta \mathrm{H}_{\text {mic }}^{\circ}-\Delta \mathrm{G}^{\circ}{ }_{\text {mic }} / \mathrm{T}
$$

The values obtained from eqn. 16 are presented in Fig. 10. A less prominent change in $\Delta \mathrm{S}^{\circ}$ mic values was observed with changing temperature. The entropy of micellization is positive indicating greater disorder/randomness in the system upon micellization of surfactants in water.

Thermodynamics of adsorption: The surface excess concentration $(\Gamma)$ of surfactant at the air-water interface as compared to that in the bulk was calculated from the slope of of linear part of surface tension against $\log \mathrm{C}$ curves from Gibbs adsorption equation ${ }^{13,31}$ which is as follows:

$$
\partial \gamma=\Sigma_{\mathrm{i}} \Gamma_{\mathrm{i}} \partial \mu_{\mathrm{i}}
$$

where, $\partial \gamma=$ change in surface tension

$\Gamma_{i}=$ surface excess concentration of ' $i$ '

$\partial \mu \mathrm{i}=$ change in chemical potential of ' $i$ '

$\partial \gamma=$ RT $\partial \ln a_{i}$

At equilibrium,

$$
\begin{aligned}
\mathrm{a}_{\mathrm{i}} & =\text { activity of ' } \mathrm{i} \text { ' in bulk phase } \\
& =\text { mole fraction } \mathrm{x} \text { activity coefficient }
\end{aligned}
$$

Therefore,

$$
\begin{aligned}
& \partial \gamma=-\operatorname{RT} \Sigma_{\mathrm{i}} \Gamma_{\mathrm{i}} \partial \ln \mathrm{a}_{\mathrm{i}} \\
& \partial \gamma=-\mathrm{RT} \Sigma_{\mathrm{i}} \Gamma_{\mathrm{i}} \partial \ln \mathrm{C}
\end{aligned}
$$

where $\mathrm{C}=$ molar concentration of surfactant in bulk

At constant temperature

$$
\begin{gathered}
\Gamma=\frac{-1}{\mathrm{RT}}\left[\frac{\partial \gamma}{\partial \ln \mathrm{C}}\right] \mathrm{T} \\
\Gamma=\frac{-1}{2.303 \mathrm{RT}}\left[\frac{\partial \gamma}{\partial \log \mathrm{C}}\right] \mathrm{T}
\end{gathered}
$$

knowing $\Gamma$, area per molecule at the interface can be calculated by using the following equation:

$$
\alpha=\frac{1 \times 10^{20}}{\mathrm{~N} \Gamma}
$$

The values of different thermodynamic parameters of adsorption at air-water interface were calculated (Table-1). It can be seen from the values that surface excess concentration and the surface area at air-water interface have regular trends with temperature. From the values we can see that the surface excess concentration is increasing which means molecules are depleting from the bulk to the surface so the area needed or available for molecules is decreasing. The surface excess concentration is an effective measure of the Gibbs adsorption at air-water interface ${ }^{21,31}$.

Using the free energy of micellization and surface excess concentration, the standard free energy of adsorption was calculated as,

$$
\Delta \mathrm{G}_{\mathrm{ads}}^{\circ}=\Delta \mathrm{G}_{\mathrm{mic}}^{\circ}-\frac{\pi_{\mathrm{CMC}}}{\Gamma}
$$

The standard entropy of adsorption was obtained from the slope of $\Delta \mathrm{G}^{\circ}$ ads $v s$. temperature graph, while the enthalpy of adsorption was calculated from the well known thermodynamic equation:

$$
\Delta \mathrm{H}^{\circ}{ }_{\text {ads }}=\Delta \mathrm{G}^{\circ}{ }_{\text {ads }}+\mathrm{T} \Delta \mathrm{S}^{\circ}{ }_{\text {ads }}
$$

The values of $\Delta \mathrm{G}^{\circ}$ ads are negative which indicate the spontaneous nature of adsorption process. The enthalpy of adsorption $\Delta \mathrm{H}^{\circ}$ ads is also negative showing the exothermic nature of adsorption process.

\section{ACKNOWLEDGEMENTS}

Miss Ayesha Niazi and Abdur Rauf are thankful to H.E.C., Islamabad for financial support through indigenous Ph.D. Fellowship Scheme and Hi-Tech Research Laboratory, Gomal University, D.I.Khan for providing equipment to carry out research activities. 


\section{REFERENCES}

1. C.A. Lipinski, Curr. Drug Discov., 14, 17 (2001)

2. $\quad$ N. Rasenack and B.W. Müller, Am. Pharm. Res., 19, 1894 (2002).

3. K. Desai, G.H. Kulkarni and A.R. Aminabhavi, J. Chem. Eng. Data, 48, 942 (2003).

4. I. Ullah, M.K. Baloch and G.F. Durrani, J. Solution Chem., 40, 1341 (2011).

5. C. Yiyun and Y. Jiepin, Phys. Chem. Liq., 44, 249 (2006).

6. C. Liu, K.G.H. Desai and C. Liu, J. Chem. Eng. Data, 49, 1847 (2004).

7. I. Ullah, M.K. Baloch and G.F. Durrani, J. Solution Chem., 41, 215 (2012).

8. H.N. Bhatti and K. Hussain, Principle of Physical Chemistry, Carvan Book House, Lahore, Pakistan (2006).

9. M.K. Baloch, G. Hameed and A. Bano, J. Chem. Soc. Pak., 24, 77 (2002).

10. D.H. Everett, Basic Principles of Colloid Science, The Royal Society of Chemistry, Cambridge, UK (1988).

11. M. Halder, Chem. Educator, 12, 33 (2006).

12. N. Jamroz, S.S. Shah and M.D.A. Alvi, Pak. J. Anal. Chem., 2, 23 (2001).

13. M.K. Baloch, F. Ahmad, A. Rauf and G.F. Durrani, J. Appl. Polym. Sci., 114, 1444 (2009)

14. T. Nakagawa and K. Kuriyama, Nippon Kagaku Zasshi, 78, 1568 (1957).

15. D.C. Poland and H.A. Scheraga, J. Phys. Chem., 69, 2431 (1965).

16. N. Nishikido, Y. Moroi, H. Uehara and R. Matuura, Bull. Chem. Soc. Jpn., 47, 2634 (1974).

17. A. Khan, G.F. Durrani, M. Usman, W. Harrison and M. Siddiq, J. Chem. Soc. Pak., 31, 731 (2009).
18. M. Siddiq Mohmood and M. K. Baloch, J. Chem. Soc. Pak., 27, 148 (2005).

19. J. Mata, T. Joshi, D. Varade, G. Ghosh and P. Bahadur, Colloids Surf. A Physicochem. Eng. Asp., 247, 1 (2004).

20. A. Khan, G.F. Durrani, M. Usman, W. Harrison and M. Siddiq, J. Chem. Soc. Pak., 31, 534 (2009).

21. M.K. Baloch, A. Farzana, A. Rauf, G.F. Durrani and G. Hameed, J. Appl. Polym. Sci., 116, 2133 (2010).

22. D.J.F. Taylor, R.K. Thomas and J. Penfold, Adv. Colloid Interface Sci., 132, 69 (2007)

23. L. Yu, T. Lu, Y.X. Luan, J. Liu and G.Y. Xu, Colloid Surf. A, 257, 375 (2005).

24. M.J. Rosen, Surfactants and Interfacial Phenomena, Wiley-Interscience Publication (1978)

25. R.C. Silva and W. Loh, J. Colloid Interface Sci., 202, 385 (1998).

26. Journal of Colloid and Interface Science (Proceeding) José L. LópezFontán, Alfredo González-Pérez, Julian Costa, Juan M. Ruso, Gerardo Prieto Pablo C. Schulz, Félix Sarmiento.

27. K. Ballerat-Busserolles, S. Rassinoux, G. Roux-Desgranges and A.H. Roux, J. Therm. Anal., 51, 161 (1998).

28. J. Jansson, K. Schillen, G. Olofsson, R. Cardoso da Silva and W. Loh, J. Phys. Chem. B, 108, 82 (2004).

29. D. Attwood and A.T. Florence, Surfactant Systems, Chapman \& Hall, New York (1983)

30. K. Gracie, D. Turner and R. Palepu, Can. J. Chem., 74, 1616 (1996).

31. Y. Li, G. Fei, Z. Honglin, L. Zhen, Z. Liqiang and L. Ganzuo, J. Therm. Anal. Calorim., 96, 859 (2009). 